\title{
Estudo de colisões usando dois smartphones
}

Pedro José Nogueira da Silva1, Jessé Silva de Souza Melo², Wagner Waulex Camargos Gudes ${ }^{3}$, Gleisivani Rodrigues Saldanha ${ }^{4}$, Robinson Viana Figueroa Cadillo ${ }^{5}$

1, 2, 3, 4, 5 Universidade Federal de Rondônia (UNIR)

Palavras-Chave: Ensino de Física, Smartphone, Colisão, Experimento.

\section{Introdução}

Apresenta-se neste trabalho uma proposta alternativa de uso de dois smartphones para o estudo experimental de choques elásticos e inelásticos (HALLIDAY, 2007). Nesse sentido, a proposta do experimento representa uma simplificação instrumental na montagem de um equipamento didático de colisões que é oferecido por empresas especializadas de experimentos de Física como PHYWE, CIDEPE ou AZEHEB ${ }^{1}$. Ou seja, visando resolver a redução de custo na aquisição do equipamento e promovendo maior acessibilidade da atividade experimental de colisões no Ensino Médio o presente trabalho tem como objetivo mostrar a potencialidade de uso do detector de presença do smartphone para o estudo de colisões entre dois planadores que percorrem linearmente sobre uma trilha de ar. A viabilidade da proposta é sustentada pela alta portabilidade do smartphone e pela acessibilidade de seus sensores favorecendo a realização de atividades práticas de Física (VIEIRA, 2013).

\section{Metodologia e materiais}

A metodologia deste projeto é de natureza experimental que seleciona, agrupa e desenvolve equipamentos didáticos usando instrumentos de laboratório e recursos de novas tecnologias. Para o presente trabalho alguns conceitos básicos de colisões foram subtraídos do modulo Leis de Colisão PHYWE ${ }^{2}$. Sendo assim, a parte experimental desta proposta usa algumas peças que fazem parte do módulo PHYWE, veja figura 1, tais como um compressor de ar, uma trilha de ar, duas máscaras retangulares $(\mathrm{m} 1 \mathrm{em} \mathrm{m} 2)$ de $10 \mathrm{~cm}$ de comprimento e dois planadores com seus respectivos acessórios de colisão, sendo que cada máscara é instalada sobre cada planador. Além disso, foram usados um disparador fabricado no laboratório e dois smartphones com o aplicativo PHYPHOX instalado. Esse último está disponibilizado gratuitamente pela loja dos smartphones com sistema operacional Android. Certamente, na proposta de experimento alternativo de colisões do módulo PHYWE, os dois smartphones substituem os sensores ópticos, a fiação e os cronômetros multifuncionais PHYWE.

Figura 1 - Esquema do experimento de colisões usando dois smartphones. O disparador está localizado no lado esquerdo do equipamento e transfere o momento linear ao planador m1.

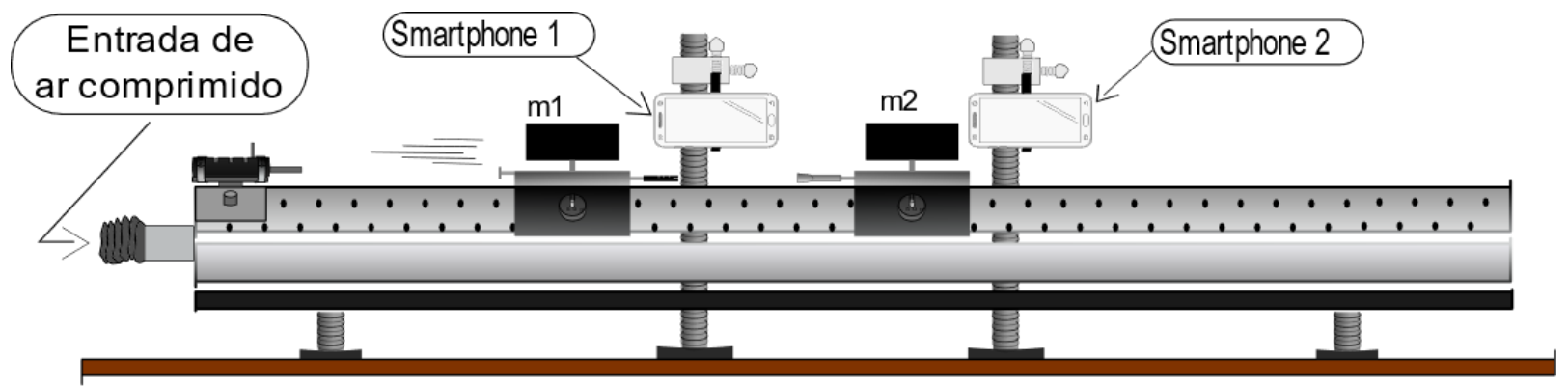

\footnotetext{
${ }^{1}$ Maiores informações técnicas sobre a trilha de ar encontra em (http://www.phywe.com) (http://www.cidepe.com.br) (<https://azeheb.com.br $>$ )

2 Informações mais especificadas sobre a lei de colisões usando o módulo PHYWE encontra em (<https://www.nikhef.nl/ h73/kn1c/praktikum/phywe/LEP/Experim/1_3_05.pdf>)

(<https://www.phywe.com/en/laws-of-collision-demonstration-track-with-a-4-4-timer.html\#tabs3>)
} 
Fazendo uso do aplicativo PHYPHOX podemos configurar o sensor de proximidade do smartphone para acionar a contagem do tempo no instante em que a máscara se aproxima ao sensor (trigger on) e, também, para desabilitar a contagem no instante em que a máscara passou pelo sensor (trigger off). Essa sequência de disparos permite medir o tempo cada vez que a máscara passa pelo sensor proximidade. Considerando essa parte técnica, a figura 1 também mostra a montagem de como os smartphones estão adaptadas no experimento para medir o tempo que realizam os planadores quando se deslocam $10 \mathrm{~cm}$ (comprimento das máscaras retangulares). Usando o disparador do laboratório transfere-se um momento linear de $15.301,28+/-361,69 \mathrm{~g} . \mathrm{cm} / \mathrm{s}$ ao planador $\mathrm{m} 1$ de $331 \mathrm{~g}$ e as colisões são produzidas entre os dois smartphones que estão distanciados $40 \mathrm{~cm}$. Portanto, considerando a leitura dos tempos para os deslocamentos das máscaras em $10 \mathrm{~cm}$ é possível medir a velocidade dos planadores antes e depois da colisão.

\section{Resultados e discussões}

Durante as atividades experimentais o momento do planador $\mathrm{m} 1$ acionado pelo disparador permanece constante antes da colisão. Os resultados da colisão elástica e inelástica usando o smartphone são mostrados na figura 2. Para a faixa de valores da razão m1/m2 $(0,6$ - 1,6), o momento total depois da colisão elástica é $15.683,5 \mathrm{~g} . \mathrm{cm} / \mathrm{s}+/-458 \mathrm{~g} . \mathrm{cm} / \mathrm{s}$. Já na colisão inelástica o momento total é $13.831,50 \mathrm{~g} . \mathrm{cm} / \mathrm{s}+/-529,39 \mathrm{~g} . \mathrm{cm} / \mathrm{s}$. Na colisão elástica é observada a garantia de repetibilidade e confiabilidade na aquisição dos dados e, portanto, na demonstração da conservação do momento linear. Já na colisão inelástica o momento total depois da colisão é menor em relação aos cálculos teóricos. Após a colisão inelástica os dois planadores formam um novo móvel aumentando a área de contato com a trilha de ar. Nessa situação, considerando constante a pressão do ar por debaixo da superfície dos planadores a força normal sobre eles aumenta e, consequentemente a força de atrito entre planadores e trilha de ar também aumenta. Dessa forma, a velocidade e momento dos planadores sobre a trilha de ar diminuem nas colisões inelásticas.

Figura 2 - Conservação de momento linear (a) na colisão elástica e; (b) na colisão inelástica. As curvas teóricas e experimentais estão representadas por linhas pontilhadas finas e grossas, respectivamente.

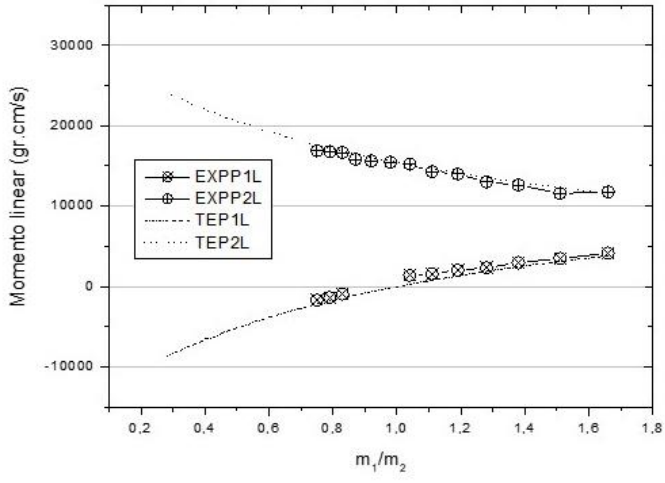

(a)

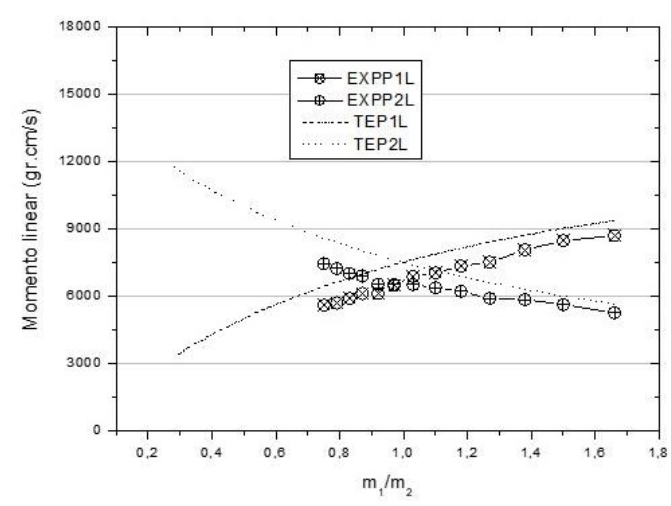

(b)

4. Conclusões

Em conclusão, a qualidade mostrada dos resultados demonstra a viabilidade de reduzir custo na aquisição de equipamentos de colisões e realmente aproximar esse material ao ensino de física nas escolas.

\section{Referências}

HALLIDAY, D.; RESNICK, R.; WALKER, J. Fundamentos de Física - Óptica e Física Moderna, v. 4, 8 ed., Editora LTC, Rio de Janeiro, 2007.

VIEIRA, L. P. Experimentos de Física com Tablets e Smartphones. Dissertação (Mestrado em Ensino de Física) - Instituto de Física, Universidade Federal Do Rio De Janeiro, Rio de Janeiro, 2013. 